\title{
Charge Contrast Imaging of Gibbsite in the Variable Pressure SEM
}

\author{
K. Robertson, R. Gauvin and J. Finch \\ McGill University, Mining, Metals and Materials Engineering, M.H. Wong building, \\ 3610 University Street, Montreal, Quebec, H3A 2B2
}

The variable pressure SEM allows for direct imaging of non-conductive samples without the necessity for a conductive coating. A pressurized chamber allows gas to be ionized, producing a positive ion, which is attracted to the sample surface where it neutralizes the negative charge build-up [1].

Charge contrast imaging (CCI) is a phenomenon which occurs in the ESEM as well as in the VP-SEM at low pressures $(\sim 170 \mathrm{~Pa})$. The cause for the CCI is still debatable, however, it is agreed that it does involve insufficient charge balancing at low pressures [2]. CCI provides detailed information on growth patterns, compositional variations and microstructures in a wide range of non-conductive materials. Cathodoluminescence (CL) was the method for this type of research previously, however, CL relies on photons instead of electrons so it does not have the same resolution. The elevated cost and complexity of CL are disadvantages when compared to CCI techniques. CCI has been observed in Gibbsite, Zircon, Sphalerite, Silica, Biotite, and Cordierite. This allows for powerful analytical techniques to be developed in the study of earth sciences [2,3].

Areas with high defect densities or microstructural features tend to appear brighter than surrounding areas, due to the charging. Varying certain operating conditions can increase the charge contrast, resulting in an image which gives greater information on compositional variation and internal structure $[2,3]$.

The research was performed on a Hitachi S-3000N VP-SEM equipped with an ESED detector. Growth rings were observed in gibbsite crystals obtained from the geology department at McGill University. Figure 1 shows the effect that beam current, beam energy and working distance have on the contrast. A filament current of $22 \mathrm{uA}$, at $30 \mathrm{kV}$ and $7.5 \mathrm{~mm}$ working distance considerably improve the charge contrast. It has been observed that the optimum working conditions for charge contrast imaging in the VPSEM, are low pressures, low beam currents, high accelerating voltages, fast scan rates, short working distances and low magnification.

\section{References}

[1] A. Mohan et al., Scanning. 20 (1998) 436-441

[2] G.R. Watt et al., American Mineralogist. 85 (2000) 17841794

[3] B.J. Griffin, Scanning. 22 (2000) 234242 


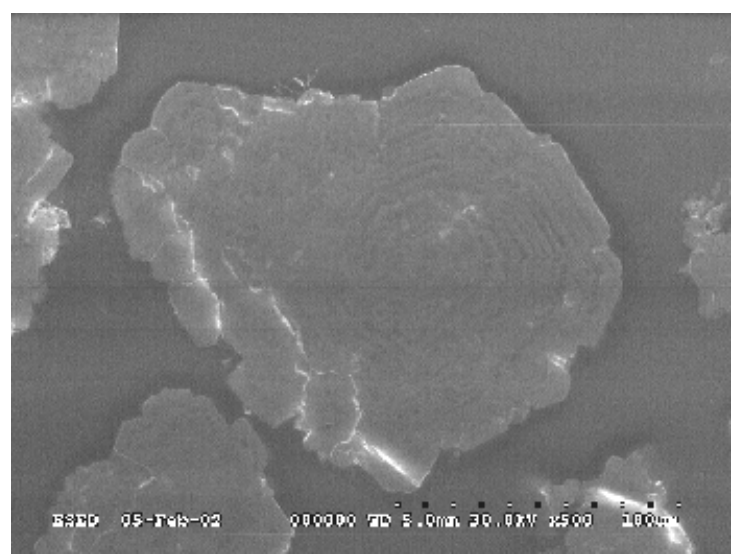

FIG. 1a)

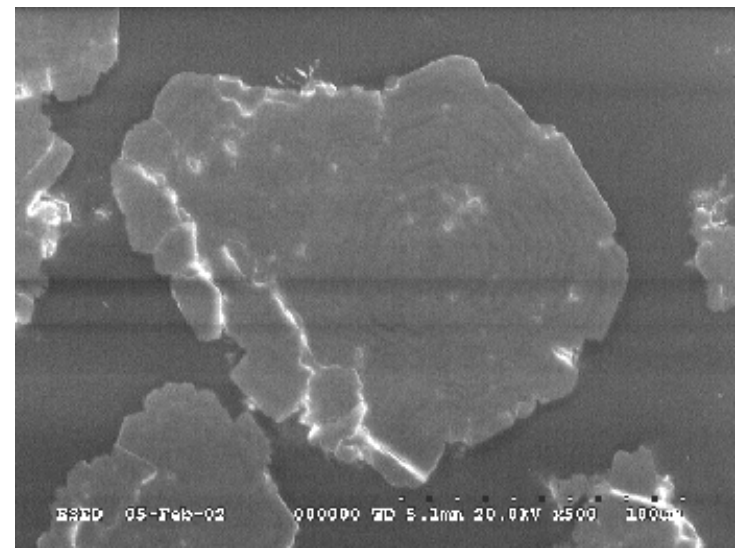

FIG. 1c)

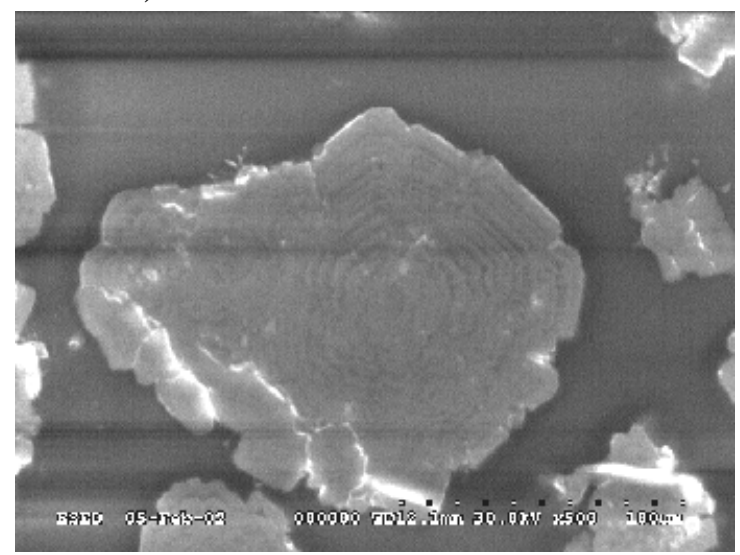

FIG. 1e)

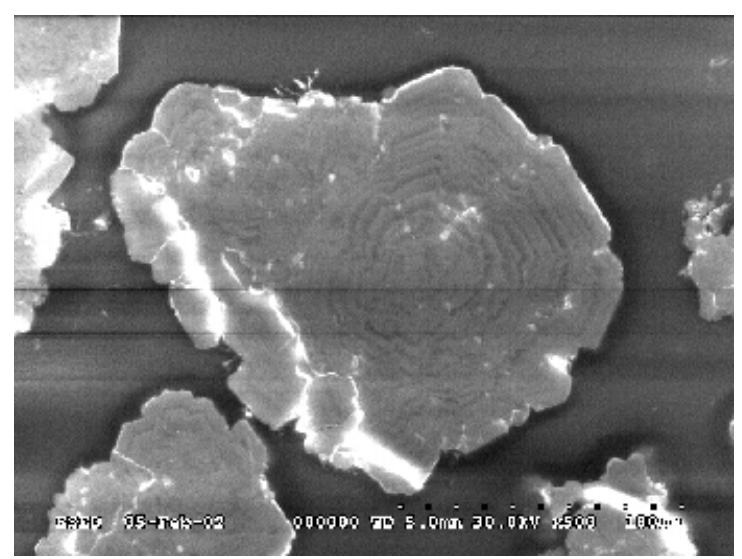

FIG. 1b)

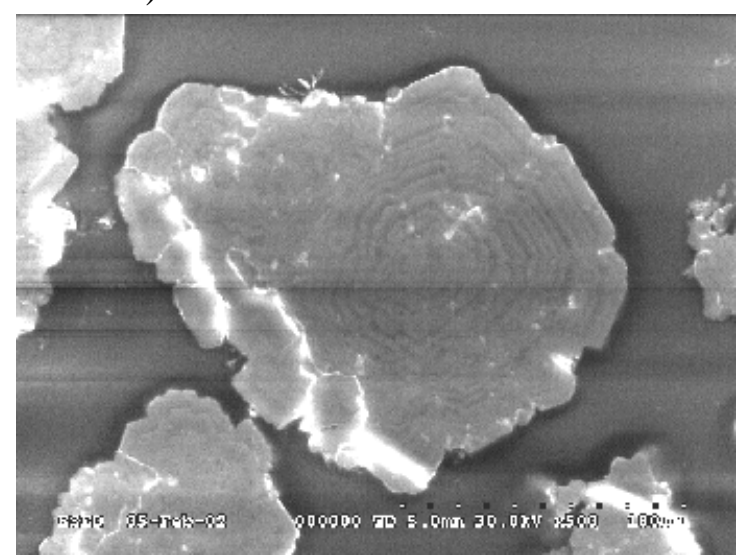

FIG. 1d)

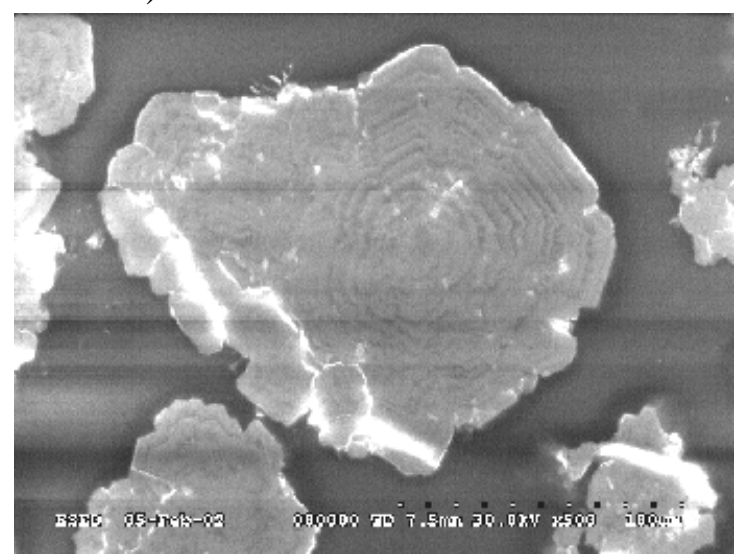

FIG. 1f)

FIG. 1. Charge contrast image of Gibbsite at $130 \mathrm{~Pa}$ and 500X magnification a) beam current $=60 \mathrm{uA}$, beam energy $=30 \mathrm{kV}, \mathrm{WD}=5 \mathrm{mmb}$ ) beam current $=22 \mathrm{uA}$, beam energy $=30 \mathrm{kV}, \mathrm{WD}=5 \mathrm{~mm}$ c) beam energy $=20 \mathrm{kV}$, beam current $=22 \mathrm{uA}, \mathrm{WD}=5 \mathrm{~mm}$ d) beam energy $=30 \mathrm{kV}$, beam current $=22 \mathrm{uA}, \mathrm{WD}=5 \mathrm{mme}$ ) $\mathrm{WD}=12 \mathrm{~mm}$, beam current $=100 \mathrm{uA}$, beam energy $=30 \mathrm{kV}$ f) $\mathrm{WD}=7.5 \mathrm{~mm}$, beam current $=22 \mathrm{uA}$, beam energy $=30 \mathrm{kV}$, 